\title{
Sobre principios de la representación arquitectónica ${ }^{1}$
}

Lorena Valdivia Arquitecta, Pontificia Universidad Católica de Chile

La distancia de Chile a los centros tradicionales de la cultura arquitectónica, lejos de limitar el desarrollo local, le ha conferido carácter y temple. Consecuencias directas de esta condición periférica son la preocupación por la representación y la atención a la manera en que se aprende arquitectura si el objeto de estudio está fuera de alcance.

En su conferencia para el legendario Darmstädter Gespräch en 1951 se quejaba el profesor arquitecto y teórico de la arquitectura alemán Rudolf Schwarz por el verdadero río de libros de arquitectura editados por cientistas del arte y compuestos en gran parte por fotografías, allí donde antes sólo se encontraban dibujos a escala. A continuación destacaba cuán inadecuado y en el fondo indigno sería ese método para enfrentar grandes arquitecturas. Finalmente agrega:

"La arquitectura ha desarrollado su propio lenguaje, mejor dicho, su propio método para componer sus partituras, el cual contempla: planta, elevación y corte. A eso se le agrega la escala y con eso se termina la cosa. Así habla arquitectura. Lo que cada uno en esa planta pudiera, quisiera o no quisiera experimentar, es absolutamente sin importancia en ese lenguaje" ${ }^{2}$.

Casi treinta años antes y desde una estricta postura orientada a la práctica, calificaba el también arquitecto Bruno Taut (en un corto artículo de explícito título: Qué es perspectiva? Cuando un cadáver cierra un ojo) la perspectiva como "el más grande obstáculo para el construir":

"El arquitecto de la Edad Media podía construir, precisamente porque no podía dibujar geometría descriptiva ni perspectivas... la potencia constructiva de los arquitectos medievales disminuye en la medida que ésta sucumbe al surgimiento de la moda científica" (Taut, 1920).

El arquitecto va finalmente más allá y no sólo sentencia la perspectiva, sino incluso "el dibujar mismo" como "lo más opuesto al construir", desaprobando para la arquitectura incluso el puro ejercicio de preguntarse por una representación arquitectónica adecuada.

Por supuesto que ese pensamiento en sí mismo no era nada nuevo. Animados por el mismo espíritu reaccionan la mayoría de los teóricos de la arquitectura del Renacimiento, entre ellos Alberti, Rafael y Barbaro ${ }^{3}$, cuando establecen las proyecciones ortogonales en planta, corte y elevación como los únicos modos de representación arquitectónica necesarios y suficientes, rechazando al mismo tiempo la perspectiva como medio válido de representación arquitectónica. Aquella perspectiva, cuyas líneas fugadas impiden la lectura de medidas exactas, será calificada como un instrumento del pintor, representativa, imitativa, engañosa, conducente a error y sólo información adicional para convencer al cliente.

Ingenieros militares desarrollan en el s. XVII el dibujo axonométrico, el cual permitirá mantener las medidas verdaderas del objeto en las representaciones espaciales: precisamente la tarea que al escorzo de la perspectiva le era imposible cumplir. No obstante, la tríada ortogonal será reemplazada por primera vez en el s. XVIII por la skiagraphia del matemático Monge, esto es, por elevaciones cuyas sombras arrojadas reproducían geométricamente la información de la planta. Este método conseguía una ilusión perspectívica sin sufrir las deformaciones ópticas de la convergencia de líneas fugadas, que Alberti tan radicalmente había desaprobado para la representación arquitectónica (Alberti, 1485).

En el s. XIX finalmente, en la época de la École Royale Polytechnique de París, se argumentará nuevamente contra el uso de efectos atmosféri-
Far from being restrictive, distance from Chile to traditional cultural centers has given to its architecture fortitude and courage. This peripheral condition has resulted in attention to representation means and concerns about the way architecture is learnt while being distant from its object of study.

cos, sombras o perspectivas, ya que según Durand, "el fin más esencial de la arquitectura no es agradar a los ojos” (Durand, 1805). A pesar de eso, el método desarrollado por Monge en 1795 será el método preferido en las escuelas de arte hasta aproximadamente $1950^{4}$

Enseñada en las escuelas de ingeniería desde fines del s. XIX y descubierta por los arquitectos recién en la primera mitad del s. XX (ciertamente influenciados por el inesperado éxito de las publicaciones de

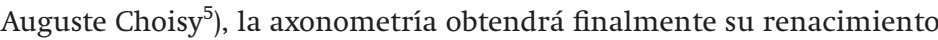
teórico-arquitectónico mucho más tarde, recién en los años ochenta. Aquella discusión girará nuevamente en torno al rol que a ambos tipos de representación -con o sin escorzo- se les asigna dentro del proceso de proyecto. Sin necesidad de ser rechazada absolutamente, la perspectiva será formulada como un servicio al cliente, mientras que la axonometría como un instrumento de trabajo propio del taller del proyectista. La axonometría -como modo de representación relacionado al objeto- representa lo que del objeto se sabe, mientras que la perspectiva -como modo de ver relacionado al observador- representa lo que del objeto se ve ${ }^{6}$. Qué tan lejos llegan a estar las funciones atribuidas tanto a la proyección ortogonal como a la perspectiva en la historia de la arquitectura, demuestra precisamente este último ejemplo si es que reemplazamos la palabra axonometría por proyección ortogonal.

Esta necesidad de rechazar la perspectiva y de formular teóricamente la tríada planta-corte-elevación para la representación arquitectónica tiene su origen -como tantas otras hipótesis de la teoría de la arquitectura- en el canon vitruviano. En el único tratado de arquitectura de la antigüedad del que se tenga noticia, define Vitruvio (88?-26? a.C.) las tres "species" de representación: orthographia, ichnographia, scaenographia ${ }^{7}$, que "los griegos llaman ideae"8, algo así como "formas o imágenes del objeto que nacen en la cabeza y son transmitidas al papel”, comenta Barbaro (Barbaro, 1556). Específicamente define Vitruvio el concepto scaenographia como "la representación de una arquitectura en figura perspectívica, que muestra junto a la fachada también la vista lateral". De esta manera y nombrado así porque sería un "invento de la pintura del teatro griego alrededor del 500 a.C.”, es como el dibujo en perspectiva vendrá recomendado por Vitruvio en forma bastante ambigua.

Esta formulación de Vitruvio será lo suficientemente vaga para que de ahí en adelante, toda la discusión teórica sobre el dibujo arquitectónico -sobre todo en el Renacimiento y hasta fines del s. XVIII- se desarrolle casi exclusivamente en torno a la interpretación de la tercera idea vitruviana -scaenographia-, la que será alternadamente traducida como corte (sciographia) o como perspectiva (scenographia). Desde el redescubrimiento del texto de Vitruvio en el año 1415 se convierte este famoso pasaje en uno de los problemas clásicos de la exégesis vitruviana (Bartoli, 1978) ${ }^{9}$. Según Wolfgang Lotz, nada menos que a partir de esa discusión se originarán más tarde "los dos métodos con los cuales el dibujo arquitectónico renacentista representará el espacio interior: el corte con perspectiva y el corte con proyección ortogonal” (Lotz, 1956). 


\section{' Parte de las ideas reproducidas en este texto pertenecen a mi trabajo de doctorado en proceso Principios de representación arqui- tectónica: el uso de la proyección ortogonal en los 'Quattro Libri' de Palladio. Este se efectúa bajo la tutela del prof. Dr.-Ing. Fritz Neumeyer (director del Instituto de Teoría de la Arquitectura Universidad Técnica de Berlín) prof. Dr. Günter Abel (co-director del Instituto de Filosofía Teoría e Historia de las Ciencias y Técnicas, Universidad Técnica de Bernín) y prof. Dr. Branko de Berlin) y prof. Dr. Branko Mitrovic (profesor de Historia y Institute la Arquitectura, Unitec, , istitute of Technology, Auckland, Nueva Zelanda). Este trabajo en proceso fue objeto de las gentiles arquitecto y profesor de}

\section{de Arquitectura de la P.U.C PhD Universidad de Cambridg Inglaterra) y José Quintanilla (arquitecto y Dr. Universidad Politécnica de Barcelona). \\ 2 De esta legendaria conferencia provienen entre otros, las cono- cidas contribuciones del prof. Dr. Martin Heidegger Bauen Wohnen Denken (Construir, habitar, pensar) y José Ortega y Gasset Der Mythus des Menschen hinter der Technik (El mito del hombre detrás de la técnica). \\ ${ }^{3}$ Además del tratado de Alberti De re aedificatoria $(\mathrm{II}, 1)$, para la De re aedificatoria (II, I), para la al Papa Leo X ver los textos de Vogel, Golzio y Barbaro. \\ ${ }^{4}$ Para la historia del término}

skiagraphia en la antigüedad y tambien como antidoto, revisar el texto de Eva Keuls Skiagraphia Once Again.

5 Entre otros, L'Art de bâtir chez les Romains y L'Art de bâtir chez les Egyptiens.

6 Como importantes ejemplos para la revisión de esta discusión en la Europa de los años ochent se consideran algunos artículos para la revista especializada dalos, listados en la bibliografia.

7 Sólo la mera colección de las interpretaciones, que mediante las distintas traducciones han sido las distintas traducciones han sido hechas de este famoso pasaje arquitectura, bastaría para hacer un trabajo de doctorado. Labor

\section{que parece haber sido asumida por Gunar Thom en la ETH de Zürich.}

8 El concepto ideae aparece nombrado sólo una vez en todo el tratado vitruviano $(1,2,2)$. Según Georg Germann no tendrí un significado filosófico, sino principalmente técnico.

9 La autora intenta explicar estos tres conceptos mediante la -al menos desde el Renacimientofrecuente interpretación de éstas como convenciones de representa ción y como etapas del proceso de proyecto y de construcción.

10 En esta obra casi estándar el autor expone cómo la perspectiva en realdad y en los términos más generales, no es inventada, sino

\section{más bien descubierta. Y no sólo na vez, sino al menos dos veces: en la Antigüedad y en el Renaci- miento, para agregar finalmente el invento de la fotografía como la tercera instancia. \\ " De la misma idea son, entre otros, Manfredo Tafuri, Carlo Giulio Argan y Yve-Alain Bois. \\ 12 Para una revisión crítica de la "arquitectura digital después de la primera ola de entusiasmo" véanse los textos de Mario Carpo. \\ 13 Excelente tratamiento del tema formulado en este artículo, desa- rrollado en un contexto mucho más amplio. \\ El título y muchas de las ideas aquí reproducidas agradezco al}

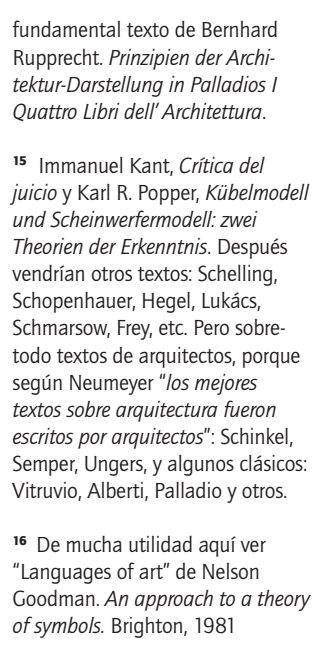

fundamental texto de Bernhard Rupprecht. Prinzipien der Archektur-Darstellung in Palladios 15 Immanuel Kant, Crítica del rl R. Popper, Kübelmodel Theorien der Erkenntnis. Despu (t) Schmarsow, Frey, ge, Puka sobre os de arquitectos, porque según Neumeyer "los mejores textos sobre arquitectura fueron Semperitos Vitruvio, Alberti, Palladio y otros. Goodman. An approach to a theo of symbols. Brighton, 198
Independientemente de las razones -ya sea por la cientificidad del principio geométrico euclidiano del Renacimiento, por la veracidad de la geometría descriptiva de Gaspard Monge, por la instauración de un lenguaje especializado de la arquitectura frente a la invasión fotográfica o justamente en contra de la obsesión científica en favor de una práctica constructiva adecuada a fines de los años veinte- es importante notar que, en todos los casos, la discusión sobre la perspectiva aparece como sintomática del cuestionamiento sobre la representación arquitectónica válida, adecuada y suficiente, es decir, del cuestionamiento sobre el lenguaje legítimo de la arquitectura. En efecto, cada redescubrimiento de la perspectiva (Gioseffi, 1957) ${ }^{10}$ trae consigo un correspondiente rechazo de ese mismo método de proyección para la arquitectura. Y lo que será más importante aún, cada uno de esos momentos entenderá el dibujo arquitectónico no sólo como un documento que contiene toda la información necesaria, sino que hará referencia a la función analítica de la representación arquitectónica -también en el proceso de proyecto- y contendrá la misma renuncia a la predominancia del carácter ilusionístico de la representación en perspectiva.

Formulada de esta manera a través del tiempo, se puede entender semejante definición de la perspectiva como una técnica pictórica no adecuada para la arquitectura, y más importante aún, la paulatina consolidación teórica de la proyección ortogonal, como indicio para la codificación definitiva del método correcto y legítimo del dibujo arquitectónico en planta, corte y elevación. Método que Palladio, siguiendo la huella de Bramante, Rafael y Antonio da Sangallo El Joven, llegará a establecer definitivamente en sus Quattro Libri (fig. 1 y 2). Aunque la tríada planta-corte-elevación sea tan antigua como la teoría de la arquitectura misma, será Palladio con sus Cuatro Libros el que la convertirá por vez primera en un principio universal ${ }^{11}$.

Sólo el hecho que, a pesar del rasante desarrollo de la representación arquitectónica -a estas alturas también computacionalmente asistida ${ }^{12}$-, estos tres modos (planta, corte y elevación) todavía constituyan el patrón básico e incluso suficiente para una legítima representación arquitectónica que no necesita el desvío por la vía de la perspectiva, convertía a esta bien conocida proyección ortogonal en un objeto digno de estudio.

Como se puede ver, el problema de la transmisión de ideas arquitectónicas es un problema tan antiguo como la arquitectura misma (Carpo, $1998)^{13}$. Lo importante en esta comprimida introducción al tema de mi doctorado sobre los principios de representación arquitectónica en el Renacimiento ${ }^{14}$, es justamente el punto de partida. El impulso inicial viene de una experiencia estudiantil y docente muy simple, muy obvia: Cuando estudiaba obras de arquitectura en nuestra escuela en Chile, lo hacía generalmente "a distancia" a través de libros y revistas especializadas. La mayoría de las obras estudiadas se encontraban incluso fuera de nuestro continente y me habían sido transmitidas principalmente a través de imágenes. Obviamente el encuentro con esas obras sería, si no siempre brutal, al menos sin excepción, sorprendente.
Esta condición inicial ponía inmediatamente el rol de la representación arquitectónica en el centro de la discusión. ¿Qué se necesita para reemplazar esa falta de experiencia in situ? ¿Cómo se debe aprender y enseñar arquitectura a partir de su representación? ¿Son estas convenciones y notaciones suficientemente neutrales? ¿Por qué es importante seguir estudiando obras de esa manera?... eran las preguntas que surgían instantáneamente.

Con estas ideas sobre la mesa se llevó a cabo la primera avasalladora corrección del tema ante el profesor guía prof. Dr-Ing. Fritz Neumeyer, evento que hoy, con una vista ya retrospectiva, llegaría a definir como crucial para el desarrollo del trabajo y para la revisión crítica de mi formación en la escuela.

La primera crítica de mi profesor fue que mis "esquemas de pensamiento eran del siglo pasado" (!) y me dio a leer a Kant y a Popper, entre otros ${ }^{15}$. Mi propuesta resultó no ser un tema de doctorado, sino uno de los problemas clásicos a los que se ha visto, todavía se ve enfrentado y siempre se enfrentará todo arte, toda técnica, toda ciencia. Sin embargo, suponiendo que yo fuera capaz de formularlo como tema de investigación científica -y esta última palabra se volvería la más importante- debía ser capaz de argumentarlo sin imágenes y por sobretodo: sin ejemplos! ¿Cómo escribir sobre la representación sin referirse a imágenes? ¿Cómo definir un concepto sin referirse a ejemplos?

Sólo el ejercicio de traducción banalizaba ideas que en castellano podían ser muy sugerentes. La ambigüedad del concepto castellano "representación” desaparecía al optar por una de las al menos 3 posibles palabras que en alemán existían como traducción. Esto precisaba casi por arte de magia las ideas, pero las privaba de la potencia sugerente inicial -casi poética- que tenían originalmente. Y antes que todo, las convertía en una decisión, en una interpretación.

Para no caer en la anécdota: lo que había detrás de todo eso es que, tanto la representación arquitectónica como la experiencia arquitectónica in situ son igual e indistintamente una pura interpretación. Lo importante entonces no era cuáles son los contenidos y las ideas arquitectónicas transmitidas -o sea las interpretaciones- sino cómo son transmitidas ${ }^{16}$. "Los hechos no existen, sólo existen interpretaciones". El único hecho es que todo es interpretación. Con esta frase fijaba mi corrector mi incapacidad de definir y hablar con precisión de los conceptos. El punto es que esta incapacidad -que en el fondo era la carencia de una técnica que se puede entrenar- era también una radiografía de nuestro sistema de estudio, no sólo universitario, sino también escolar. Sin ánimo de polemizar, el problema tenía que ver con ese tratar de describir los contenidos transmitidos y no las formas de transmitirlos y, finalmente, con aquella aproximación más bien empírica que tenemos a la obra y a los problemas de la arquitectura en nuestra escuela. Método ni mejor ni peor, sólo radicalmente opuesto al que se me presentaba como científico. Y es justamente esa metodología el mayor obstáculo que se tiene cuando 


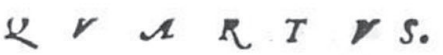

Ichnographit, orthographia, of Schiographia adis periptcia.

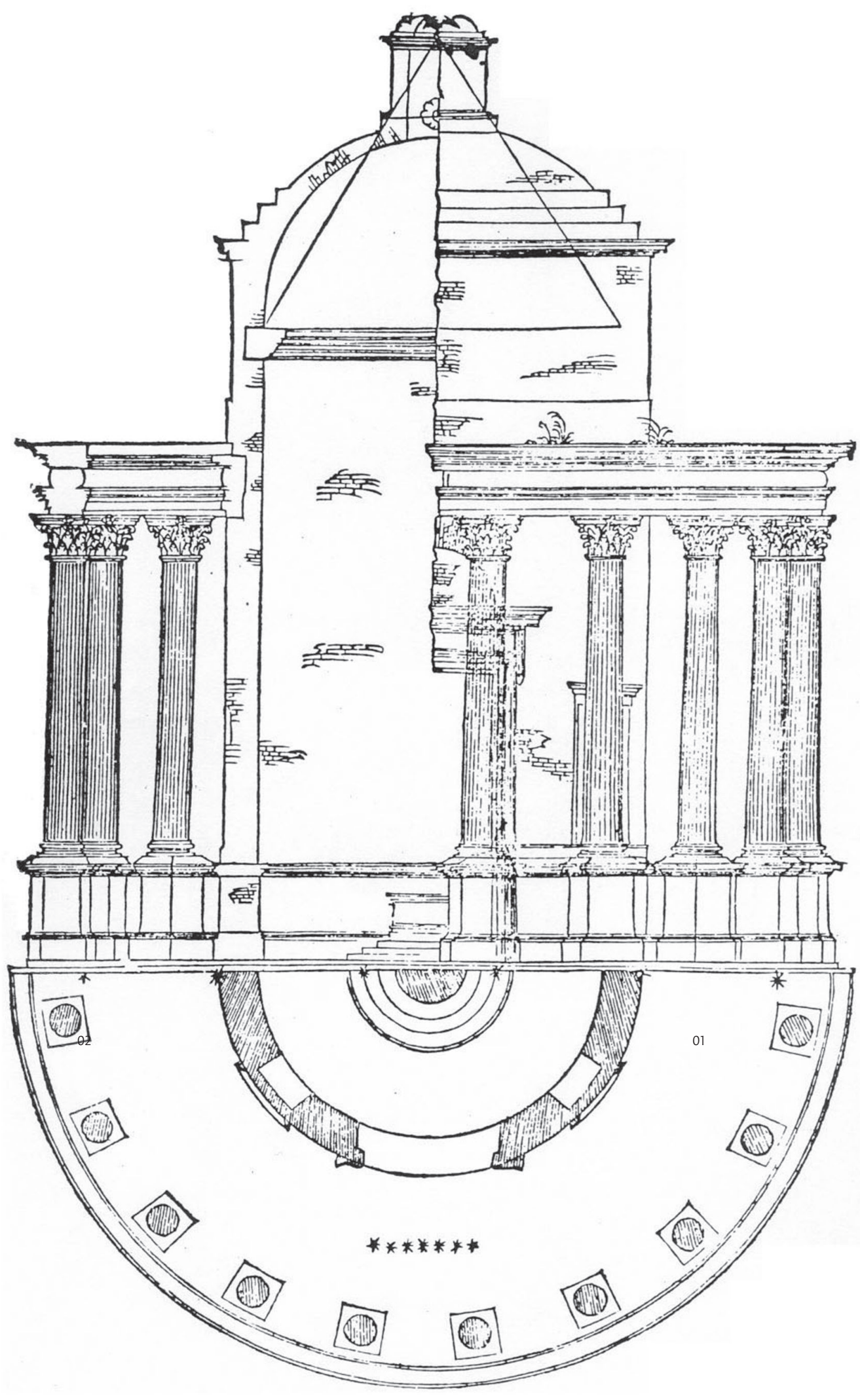

Dos dibujos ejemplares que caracterizan el dibujo arquitectónico palladiano: 01 Dibujo de Palladio del Templo redondo llamado peripteros para la edición del Vitruvio de Daniele Barbaro, I dieci libri dell' architettura di M. Vitruvio, tradutti e commentati. Planta, corte y elevación unidos en un único dibujo, que además es transparente en el portal de acceso y contiene las proporciones geométricas de la cúpula y la linterna

02 Detalle del capitel iónico en I quattro libri dell' architettura de Andrea Palladio Un ćŕcico del dibujo palladiano, de una sintesis calidad rava (1) hasta en el más mínimo detalle no existe ninguna confusión. La estructura regular del capitel permite mostrar sólo un cuarto de la planta.

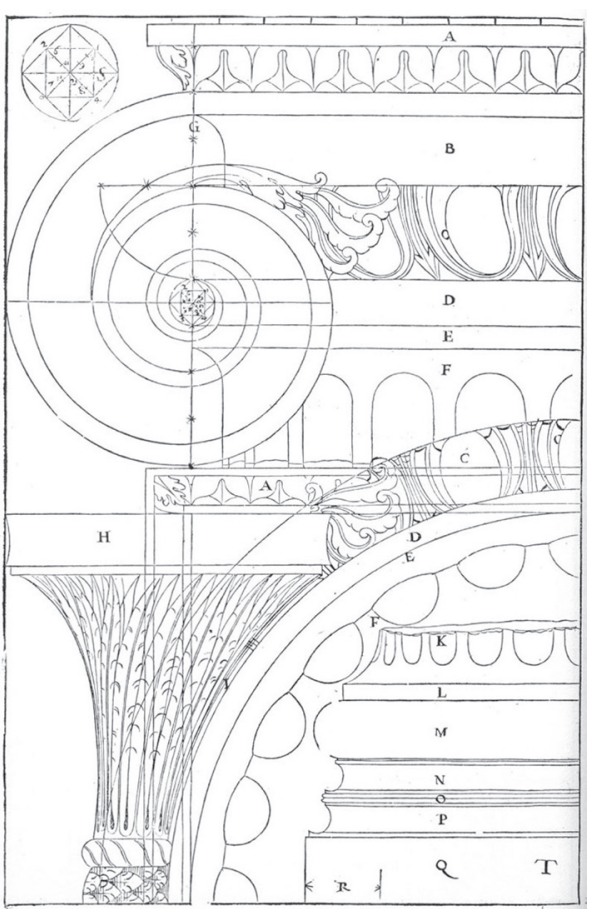


17 Ordenanza de doctorado de la universidad: Promotionsordnung zur Doktorin oder zum Doktor der Ingenieurwissenschaften (Dr.-Ing.) an der Technischen Universität Berlin. 2000. <http://www.cs.tu-berlin. $\mathrm{de} / \mathrm{cs} / \mathrm{fb} /$ /Promotionsordnungen/ Dr_lng.html>

se estudia en un sistema distinto al propio. Una vez aprendido, el resto es casi sólo mero trabajo. Así el tema se convierte en una excusa para hacer un ejercicio de investigación y en un objeto por el que ni siquiera es necesario sentir simpatía. La simpatía por un tema no lo hace interesante, ni lo convierte en un objeto legítimo de estudio, termina mi profesor. Como determina el reglamento de doctorado de la universidad, durante el proceso de doctorado debe ser demostrado que el solicitante posee la capacidad de hacer una contribución a la investigación y desarrollo de las ciencias, por medio de una disertación escrita y una exposición oral exitosa ${ }^{17}$. A diferencia de un proyecto de título o de un trabajo de magíster, el doctorado no es un trabajo propositivo, ni la expresión de una opinión personal, sino un trabajo independiente e inédito y, por sobre todas las cosas, un modesto aporte a un cuerpo de conocimiento mayor, llenando uno de sus nichos vacíos. Se trata de demostrar que se es capaz de plantear una pregunta y de evaluar adecuadamente los resultados de la respectiva investigación, situando éstos últimos legítimamente en la correspondiente especialidad elegida: en este caso, no en la historia ni en la crítica, sino en la teoría de la arquitectura. Es decir, se trata de habérselas con el método científico, que en términos generales no es más que la discusión sistemática de un problema planteado. El estilo debe ser por eso, concreto y preciso. El argumento debe ser inteligible, inequívoco, deductible y comprobable.

Todos aspectos de uno de los problemas más antiguos de la arquitectura: la transmisión legítima de contenidos. Problema ya formulado por Vitruvio -en el primer capítulo del primer libro del primer tratado de arquitectura- como la oposición entre "la cosa significada y aquello que significa" y tematizado a partir de ese momento por los arquitectos de todos los tiempos. Problema al que de alguna u otra manera se verá siempre enfrentado cada arquitecto. Nada nuevo, sólo sucede que ese "definir conceptos sin ejemplos” era lo más parecido a la sentencia del profesor Hernán Riesco: "sensibilidad es precisión”, que al fin he podido entender. ARQ

\section{Bibliografía}

Alberti, Leon Battista. De re aedificatoria. Original de 1450-1485. Wiss. Buchgesellschaft, Darmstadt, 1991. / Argan, Carlo Giulio. "Palladio und der Palladianismus”. Original de 1984. Kunstgeschichte als Stadtgeschichte. Fink, Munich, 1989. / Barbaro, Daniele: I dieci libri dell' architettura di M. Vitruvio, tradutti e commentati... Original de 1556. Il Polifilo, Milán, 1987. / Barbaro, Daniele. La Pratica della perspettiva di Monsignor... Original de 1569. Forni, Bolonia, 1980. / Bartoli, María Teresa. “Orthographia, ichnographia, scaenographia”. 2000 anni di Vitruvio. Studi e documenti di architettura № 8. Teorema, Florencia, 1978. / Bois, Yve-Alain. "Metamorphosen der axonometrie”. Daidalos № 1. Bertelsmann, Berlín, 1981. / Carpo, Mario. Architecture in the age of printing: orality, writing, typography, and printed images in the history of architectural theory. MIT Press, Cambridge, 2001. / Carpo, Mario. "How do you imitate a building that you have never seen? Printed images, ancient models, and handmade drawings in Renaissance architectural theory”. Zeitschrift für Kunstgeschichte № 64 . Deutscher Kunstverlag, Berlín, 2001. / Carpo, Mario. “Die digitale Architektur nach der ersten Begeisterungswelle. Vom irrationalen Überschwang zur irrationalen Mutlosigkeit”. Thesis Vol. 49 № 3. Bauhaus-Universität, Weimar, 2003. / Choisy, Auguste. L'Art de bâtir chez les Romains. Ducher, París, 1873. / Choisy, Auguste. L'Art de bâtir chez les Egyptiens. E. Rouveyre, París, 1904. / Durand, Jean Nicolas Louis. Original de 1802-1805. Précis des leçons d'architecture données à l'École Royale Polytechnique. Abriß der Vorlesungen über Baukunst gehalten an der königlichen polytechnischen Schule zu Paris. Herder, Carlsruhe. 1831. / Frommel, Christoph Luitpold. The architectural drawings of Antonio da Sangallo the Younger and his circle. MIT Press, Cambridge, 1994. / Germann, Georg. Einfüh- rung in die Geschichte der Architekturtheorie. Wiss. Buchgesellschaft, Darmstadt, 1987. / Gioseffi, Decio. "Perspectiva artificialis. Per la storia della prospettiva. Spigolature e appunti”. Istituto di storia dell' arte antica e moderna № 7 . Facoltà Lettere e Filosofia Università di Trieste, 1957. / Golzio, Vincenzo. Raffaello nei Documenti, nelle documenti nelle testimonianze dei contemporanei e nella letteratura del suo secolo. Pontificia Insigne Accademia Artistica dei Virtuosi al Pantheon, Ciudad del Vaticano, 1936. / Goodman, Nelson. Languages of art. An approach to a theory of symbols. Harvester Press, Brighton, 1981. / Goodman, Nelson y Cath erine Z. Elguin. Reconceptions in philosophy and other arts and sciences. Routledge, Londres, 1988. / Hart, Vaughan y Peter Hicks. Paper palaces. The rise of the Renaissance architectural treatise. Yale University Press, New Haven - London, 1998. Jormakka, Kari. Geschichte der Architekturtheorie. Selene, Viena, 2003. / Kant, Immanuel. Kritik der Urteilskraft. Original de 1781. Meiner, Hamburgo, 2001. | Keuls, Eva. "Skiagraphia once again”. American Journal of Archaeology Vol. 79 № 1. Archaeological Institute of America, Boston, 1975. / Kruft, HannoWalter. Geschichte der Architekturtheorie. Von der Antike bis zur Gegenwart. C.H. Beck, Munich, 1986. / Lang, S. "De lineamentis: L.B. Alberti's use of a technical term". Journal of the Warburg and Courtauld Institutes Vol. XXVIII. Warburg Institut, Londres, 1965. / Lotz, Wolfgang. "Das Raumbild in der italienischen Architekturzeichnung der Renaissance”. Mitteilungen des Kunsthistorischen Institutes in Florenz Vol. VII. Max-Planck-Institut, Florencia, 1956. / Mitrovic, Branko. "Objectively speaking”. Journal of the Society of Architectural Historicians № 52. University of Pennsylvania, Filadelfia, 1993. / Mitrovic, Branko. "Leon Battista Alberti and the homogeneity of space". Journal of the Society of Architectural Historicians Vol. 63 № 4. University of Pennsylvania, Filadelfia, 2004. / Moravánszky, Ákos y Katalin M. Gyöngy. Architekturtheorie im 20. Jahrhundert. Eine kritische anthologie. Springer, Viena, 2003. / Oechslin, Werner. "Geometrie und linie. Die Vitruvianische Wissenschaft von der Architekturzeichnung”. Daidalos № 1. Bertelsmann, Berlín, 1981. / Oechslin, Werner. "Architektur, Perspektive und die hilfreiche Geste der Geometrie". Daidalos № 11. Bertelsmann, Berlín, 1984. / Olschki, Leonardo. "Die Literatur der Technik und der angewandten Wissenschaften vom Mittelalter bis zur Renaissance". Geschichte der neusprachlichen wissenschaftlichen Literatur № 1 . Winter, Heidelberg, 1919. / Pahl, Jürgen. Architekturtheorie des 20. Jahrhunderts. Prestel, Munich, 1999. / Palladio, Andrea. I quattro libri dell' architettura. Original de 1570. Olms, Venecia, 1979. / Popper, Karl R. "Kübelmodell und Scheinwerfermodell: zwei Theorien der Erkenntnis”. Objektive Erkenntnis. Ein evolutionärer Entwurf. Hoffmann und Campe, Hamburgo, 1973. / Reichlin, Bruno. "Spiegelungen. Wechselbeziehungen zwischen Konzept, Darstellung und gebauter Architektur”. Daidalos № 1. Bertelsmann, Berlín, 1981. / Rupprecht, Bernhard "Prinzipien der Architektur-Darstellung in Palladios I Quattro Libri dell' Architettura”. Vierhundert Jahre Andrea Palladio. 1580-1980. Winter, Heidelberg, 1982. / Schneider, Bernhard. "Perspektive bezieht sich auf den Betrachter, Axonometrie bezieht sich auf den Gegenstand”. Daidalos № 1. Bertelsmann, Berlín, 1981. / Schwarz, Rudolf. "Das Anliegen der Baukunst”. Das Darmstädter Gespräch 1951. Mit den wegweisenden Vorträgen von Schwarz, Schweizer, Heidegger, Ortega y Gasset. Vieweg, Braunschweig, 1991. / Silvetti, Jorge. "Perspektive und der neidische Blick auf die Renaissance”. Daidalos № 11. Bertelsmann, Berlín, 1984. / Szambien, Werner. "Architekturdarstellung an der Pariser Ecole Polytechnique zu Beginn des 19. Jahrhunderts”. Daidalos № 11. Bertelsmann, Berlín, 1984. / Tafuri, Manfredo. "La norma e il programma: il Vitruvio di Daniele Barbaro”. Vitruvio I dieci libri dell' architettura. Il Polifilo, Milán, 1987. | Taut, Bruno. "Was ist Perspektive? - Wenn eine Leiche ein Auge zukneift". Frühlicht. Zirkel, Berlín, 1920. / Thoenes, Christof. "Vitruv, Alberti, Sangallo. Zur Theorie der Architekturzeichnung in der Renaissance”. Hülle und Fülle Verlag und Datenbank für Geisteswissenschaften, Alfter, 1993. / Vogel, Julius. Bramante und Raffael. Ein Beitrag zur Geschichte der Renaissance in Rom. Klinkhardt \& Biermann, Leipzig, 1910. 